\title{
Contributions of Climatic Factors to Interannual Variability of the Vegetation Index in Northern China Grasslands
}

\author{
WEI ZHAO AND ZHONGMIN HU \\ School of Geography, South China Normal University, Guangzhou, China \\ Qun Guo, GenAn Wu, RuRu CHEN, AND SHENGGONG LI \\ Synthesis Research Center of Chinese Ecosystem Research Network, Key Laboratory of Ecosystem Network \\ Observation and Modeling, Institute of Geographic Sciences and Natural Resources Research, Chinese Academy of \\ Sciences, and College of Resources and Environment, University of Chinese Academy of Sciences, Beijing, China
}

(Manuscript received 5 September 2018, in final form 23 October 2019)

\begin{abstract}
Understanding the atmosphere-land surface interaction is crucial for clarifying the responses and feedbacks of terrestrial ecosystems to climate change. However, quantifying the effects of multiple climatic factors to vegetation activities is challenging. Using the geographical detector model (GDM), this study quantifies the relative contributions of climatic factors including precipitation, relative humidity, solar radiation, and air temperature to the interannual variation (IAV) of the normalized difference vegetation index (NDVI) in the northern grasslands of China during 2000 to 2016. The results show heterogeneous spatial patterns of determinant climatic factors on the IAV of NDVI. Precipitation and relative humidity jointly controlled the IAV of NDVI, illustrating more explanatory power than solar radiation and air temperature, and accounting for higher proportion of area as the determinant factor in the study region. It is noteworthy that relative humidity, a proxy of atmospheric aridity, is as important as precipitation for the IAV of NDVI. The contribution of climatic factors to the IAV of NDVI varied by vegetation type. Owing to the stronger explanatory power of climatic factors on NDVI variability in temperate grasslands, we conclude that climate variability may exert more influence on temperate grasslands than on alpine grasslands. Our study highlights the importance of the role of atmospheric aridity to vegetation activities in grasslands. We suggest focusing more on the differences between vegetation types when addressing the climate-vegetation relationships at a regional scale.
\end{abstract}

\section{Introduction}

Climate is one of the major determinants for plant growth, and vegetation productivity has been largely changed in the past few decades owing to climate change (Nemani et al. 2003; Friedlingstein et al. 2006; Xu et al. 2013). In turn, vegetation is simultaneously affecting climate through biochemical cycles and biophysical feedbacks (Lee et al. 2011; Keenan et al. 2013; Zhu et al. 2017; Zhao et al. 2017). Therefore, understanding the relationship between climatic factors and vegetation activities is crucial for predicting vegetation responses and feedbacks to climate change.

Grasslands cover more than $30 \%$ of Earth's land surface (Wang and Fang 2009), serving as a critical

\footnotetext{
Corresponding author: Zhongmin Hu, huzm@m.scnu.edu.cn
}

feedback source for the global climate. It has been found that grasslands dominate the global carbon sink trend and account for the largest fraction of the interannual variation (IAV) in global biome productivity (Ahlström et al. 2015). Grasslands in arid and semiarid areas are also sensitive to global climate change (Seddon et al. 2016). Thus, clarifying the relationship between the IAV of vegetation productivity and climate change is of great importance in the field of global change ecology. As the ecosystem type with the largest terrestrial area in the country $(\sim 40 \%)$, grasslands in China (Fan et al. 2008) also have received much attention in climate change research. Studies have investigated the dominant climatic factors in affecting the IAV of vegetation productivity in grasslands in China. For example, in Inner Mongolia, the relatively warm and dry climate and associated droughts are the main factors affecting 
vegetation growth (Bao et al. 2014). Precipitation plays a key role in plant growth in the Loess Plateau (Li et al. 2015a), Xinjiang (Li et al. 2015b), and even the Tibetan Plateau (J. Yao et al. 2018). These studies have largely enhanced our understanding of how the functions of grasslands in China are affected by climatic factors. However, on the one hand, the spatial pattern of determinant climatic factors on IAV of ecosystem productivity across ecoregions and ecosystem types in grasslands in China remains unclear. On the other hand, the contributions of each climatic factor on the IAV of ecosystem productivity have not been well quantified. In particular, the role of atmospheric aridity [e.g., water vapor pressure deficit (VPD) or air humidity], which has recently been proved to be critical to the IAV of vegetation productivity in grasslands (Novick et al. 2016; Konings et al. 2017; Ding et al. 2018), has not been taken into sufficient consideration.

The contributions of climatic variables to the IAV of vegetation productivity can be quantified using statistical methods, such as correlation and regression analysis (e.g., Peng et al. 2013; Y. Yao et al. 2018) and numerical models (e.g., Mao et al. 2012; Piao et al. 2015). Most statistical methods quantify climate controls on the vegetation dynamics with a linear hypothesis (Piao et al. 2015). In fact, numerous experiments and analyses show that the trajectory of ecosystem responses to climatic factors is nonlinear (Peng et al. 2013; Yamori et al. 2014; Piao et al. 2014). Although land models have been applied to quantify the contribution of environmental factors to vegetation productivity, owing to uncertainties in model structure and parameters inconsistent or even conflicting results are produced among models (J. Yao et al. 2018). Recently, the geographical detector model (GDM) has been proposed to quantify the contribution of factors (drivers) to dependent variables (attributes or phenomenon) based on spatial stratified heterogeneity (Wang et al. 2010). The GDM can identify the connection between variables based on the consistency of their distributions (time or spatial). This technique does not require a linear hypothesis to identify the critical driving factors behind stratified heterogeneity. This method has shown good performance and is widely used in the fields of ecological, atmospheric, and geographic studies (Luo et al. 2016; Wang et al. 2016; Zhou et al. 2018). Therefore, GDM is an effective tool to quantify the contributions of various climatic factors to the IAV of vegetation productivity.

To solve the issues mentioned above, here we used GDM to quantify the contributions of climatic factors to IAV of the normalized difference vegetation index (NDVI, a proxy of vegetation productivity) in grasslands in northern China. The main objectives of this study are 1) to identify the determinant climatic factor controlling the IAV of NDVI and clarify the spatial pattern of the factor in the study region, and 2) to quantify the contribution of each climatic factor to the IAV of NDVI and clarify the difference among subregions and vegetation types. In particular, the climatic factor of atmospheric aridity (i.e., air relative humidity) was included in our analysis, which has not been paid full attention in previous studies.

\section{Materials and methods}

\section{a. Study region}

Grasslands in northern China account for more than $80 \%$ of grassland areas in China, which comprises four geographical units: Inner Mongolia, the Loess Plateau, the Tibetan Plateau, and Xinjiang. The study region is the temperate grasslands mainly distributed in Inner Mongolia, the Loess Plateau, and Xinjiang, and the alpine grasslands in the Tibetan Plateau, and a few mountain meadow grasslands (Fig. 1). Most of the study region has typically arid and semiarid climates, while the Tibetan Plateau has a typically cold and dry alpine climate. The mean annual temperature and mean annual precipitation range from $-3^{\circ}$ to $9^{\circ} \mathrm{C}$ and from 100 to $700 \mathrm{~mm}$, respectively (Guo et al. 2012; Sun and Qin 2016; Ding et al. 2018).

Three temperate grassland types are distributed along the mean annual precipitation gradient: meadow steppe, typical steppe, and desert steppe. Alpine steppe is mainly distributed in the northeast, alpine meadow is more scattered in the middle, and alpine desert steppe is mainly located northwest of the Tibetan Plateau. Mountain meadow is mainly located in northern Inner Mongolia and eastern Tibetan Plateau. The strong spatial heterogeneity in grassland types and climatic conditions governs the spatial pattern of the sophisticated relationship between climate variations and vegetation dynamics in this region.

\section{b. Datasets}

\section{1) Meteorological data}

Four climatic variables-precipitation, air temperature, relative humidity, and solar radiation-were selected to quantify their importance on NDVI variability. Precipitation, air temperature, and relative humidity from 756 nationwide meteorological stations (290 stations in this study region) in China were acquired from the China Meteorological Data Service Center website 

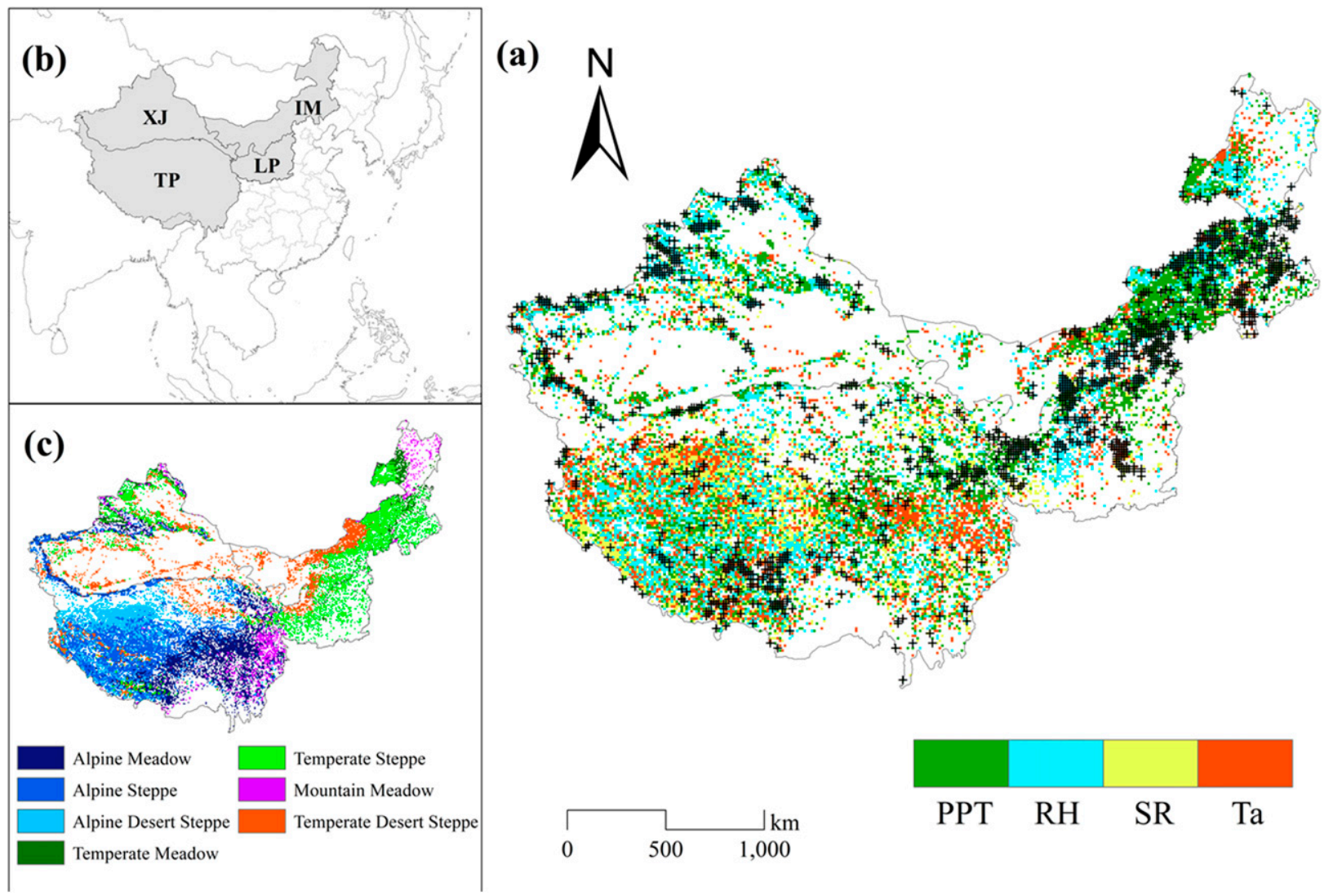

FIG. 1. (a) Spatial pattern of determinant climatic factors on the IAV of NDVI over grasslands in northern China, and the location of the study region and (b) its four subregions and (c) vegetation types. The four subregions are Inner Mongolia (IM), the Loess Plateau (LP), the Tibetan Plateau (TP), and Xinjiang (XJ). The determinant climatic factor is indicated in each grid cell including precipitation (PPT), relative humidity (RH), solar radiation (SR), and air temperature $\left(T_{a}\right)$. Grids with significant climate variability effects on grassland growth $(p<0.05)$ are labeled with cross symbols.

(http://data.cma.cn/en). Site-level solar radiation was calculated at 8-day time resolution using the Ångström formula, which relates solar radiation to extraterrestrial radiation and the duration of relative sunshine; it is the recommended algorithm of the Food and Agriculture Organization (http://www.fao.org/docrep/x0490e/ $\mathrm{x} 0490 \mathrm{e} 07 . \mathrm{htm} \#$ radiation). The site-level data were interpolated at $10-\mathrm{km}$ resolution with the ANUSPLIN software package (Hutchinson and Xu 2013), which provides an interpolation of noisy multivariate data using thin plate smoothing splines from observation data acquired from meteorological stations. ANUSPLIN is widely used for interpolation of climatic variables (e.g., Ukkola et al. 2016). The quality of the interpolated meteorological dataset has previously been fully evaluated and found to have reliable accuracy (Yu et al. 2004).

\section{2) NDVI}

NDVI is a proxy of vegetation productivity (e.g., Piao et al. 2014; Wang et al. 2017). NDVI is generated from MODIS observations with the data processed to remove clouds and then gap-filled (Liu et al. 2017). In this study, 8-day NDVI datasets covering 2000-16, derived from the National Earth System Science Data Sharing Infrastructure (http://www.geodata.cn/), were used to investigate their association with climatic factors. NDVI data were further aggregated to $10 \mathrm{~km} \times 10 \mathrm{~km}$ to match the resolution of meteorological data using the grid resample method. The dataset quality has been verified to be suitable in China (e.g., Hu et al. 2017).

\section{3) GRASSLAND CLASSIFICATION}

Grassland types and their distribution were obtained from a 1:1000 000 digitalized vegetation map of China (Editorial Board of Vegetation Map of China, Chinese Academy of Sciences 2007). We extracted the grasslands including three temperate grassland types (temperate meadow, temperate steppe, and temperate desert steppe), three alpine grassland types (alpine meadow, alpine steppe, and alpine desert steppe), and mountain grassland. Other vegetation types were not included in this study. 


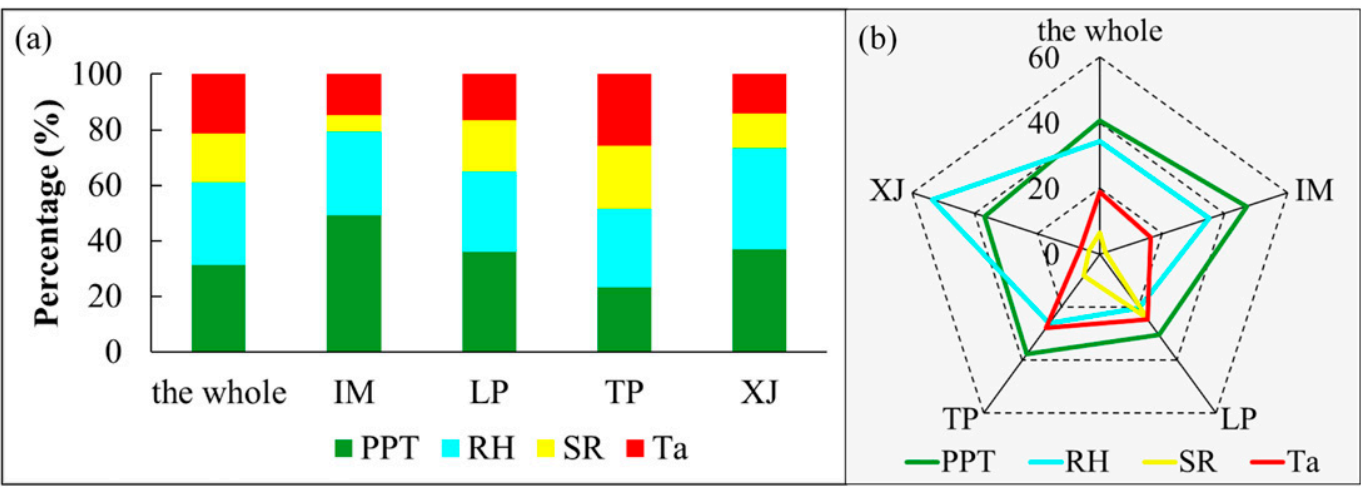

FIG. 2. (a) Area percentage of each determinant climatic factor of the whole study region and (b) the significant $(p<0.05)$ proportion area of all grids with significant effects on grassland dynamics across the grasslands of northern China (the whole) and its four subregions (IM, LP, TP, XJ). Abbreviations are defined in Fig. 1.

\section{c. Data analysis and methods}

With the time series (2000-16) of NDVI and the climatic variables, we used GDM to quantify the contribution of each climatic factor to the interannual variation in NDVI at each grid. The GDM works with categorical variables, which can be discretized using the $K$-means classification algorithm when using numerical variables. The discretization scheme with the largest $q$ value is generally selected to achieve the best performance for the GDM. The explanatory power for each climatic variable $x$ on IAV of NDVI is quantified by the power of determinant $q$ :

$$
q_{x}=1-\frac{\sum_{i=1}^{m} N_{i} \sigma_{i}^{2}}{N \sigma^{2}}=1-\frac{\mathrm{SSW}}{\mathrm{SST}},
$$

where $q_{x}\left(q_{x} \in[0,1]\right)$ is the power of the climatic factor $x$; $i=1, \ldots, m$ is the stratum (category) of NDVI for climatic factor $x ; N_{i}$ and $N$ are the total sample numbers of the $i$ stratum and overall period (2000-16), respectively; $\sigma_{i}^{2}$ and $\sigma^{2}$ are the variances of NDVI in the $i$ stratum and overall period, respectively; and SSW and SST are the within sum of squares in the $i$ stratum and total sum of squares in the overall period, respectively.

The sum (for precipitation) and mean (for NDVI, relative humidity, solar radiation, and air temperature) of the climatic variables during each growing season [day of year (DOY) 121-273] were calculated as the annual values. With the annual values of NDVI and the climatic variables in 2000-16, we quantified the contribution of each climatic factor to NDVI dynamics at an annual basis. The reason we used the mean (or sum) of each growing season rather than the whole year is that there is no plant growing during the period of nongrowing seasons of grasslands in our study region. In addition, the annual productivity was found to be mostly correlated with climatic factors in the growing season but not the whole year (e.g., Bai et al. 2004; Guo et al. 2015).

\section{Results}

\section{a. Spatial pattern of determinant climatic factors}

Figure 1 shows the distribution of the determinant climatic factors on the IAV of NDVI in the grasslands of northern China during 2000-16. Apparently, the spatial distribution of the dominant controlling factor was heterogeneous in the study region without clear transitional zones being detected. The zones of every determinant climatic factor were distributed in an interlaced manner without clear spatial demarcation and transitional transect among any two factors. The area of the precipitation determinant was concentrated on the eastern part, those of air temperature and solar radiation were located on the Tibetan Plateau, and that of relative humidity was scattered across the whole study region. Grids with significant climate variability affecting grassland growth were distributed in the hinterland of the temperate steppe and the transition zones of alpine meadows and alpine steppe.

Precipitation and relative humidity determined the IAV of NDVI in the majority of the region, accounting for $31.3 \%$ and $29.8 \%$ of the whole area, respectively, while air temperature and solar radiation accounted for $21.4 \%$ and $17.5 \%$, respectively (Fig. 2a). Areas with grassland productivity significantly constrained by precipitation and relative humidity accounted for $40.1 \%$ and $34.2 \%$, respectively, of all significant areas, much more than air temperature $(18.8 \%)$ and solar radiation (6.4\%) (Fig. 2b). Zones with more contribution (grids with significant effects) of climatic factors spread from the northeast to southwest along the regional boundary. 


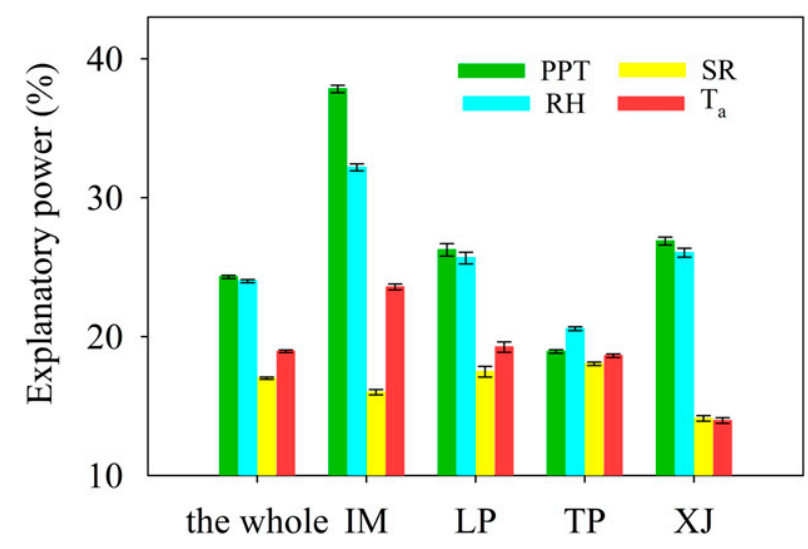

FIG. 3. Average explanatory powers of climatic factors (PPT, $\mathrm{RH}, \mathrm{SR}, T_{a}$ ) for grassland dynamics in grasslands of northern China (the whole) and its four subregions (IM, LP, TP, XJ). Bars indicate standard error. Abbreviations are defined in Fig. 1.

In general, the explanatory power of GDM showed that precipitation had the largest contribution $(24.3 \%)$ to the IAV of NDVI in the whole region, followed by relative humidity $(24 \%)$, air temperature $(18.9 \%)$, and solar radiation (17\%) (Fig. 3).

\section{b. Contributions of climatic factors to NDVI variability in different subregions}

Precipitation and relative humidity were the leading important climatic constraint factors on the IAV of NDVI for each subregion, showing rough agreement with the pattern of the whole study region. In detail, the effects of precipitation and relative humidity on the IAV of NDVI occupied $49.2 \%$ and $30 \%$ of Inner Mongolia, $36.2 \%$ and $28.8 \%$ of the Loess Plateau, $23.3 \%$ and $28.2 \%$ of the Tibetan Plateau, and $37.1 \%$ and $36.4 \%$ of Xinjiang, respectively (Fig. 2a). Grids with climatic factor significantly $(p<0.05)$ controlling the IAV of
NDVI were mainly concentrated in the middle section of Inner Mongolia and the northwestern Loess Plateau, but they were relatively scattered in the Tibetan Plateau and Xinjiang region (Fig. 1). Regarding the proportion of significant $(p<0.05)$ climatic determinant factors, precipitation was the leading factor of the IAV of NDVI in Inner Mongolia (46.9\%), the Loess Plateau (30.6\%), and the Tibet Plateau (37.8\%), while relative humidity dominated in Xinjiang (53.6\%) (Fig. 2b).

The explanatory power of precipitation and relative humidity was $37.8 \%$ and $32.2 \%$ in Inner Mongolia, $26.2 \%$ and $25.7 \%$ in the Loess Plateau, $18.9 \%$ and $20.6 \%$ in the Tibetan Plateau, and $26.8 \%$ and $26 \%$ in Xinjiang, respectively (Fig. 3). Particularly, four climatic factors had roughly equivalent contributions, with the explanatory powers of around $20 \%$ controlling the IAV of NDVI in the Tibetan Plateau. Climatic variability (the IAV of four climatic factors) had weaker regulatory effect (sum of the explanatory power of four climatic factors) on the IAV of NDVI in the Tibetan Plateau $(76.1 \%)$ than in Inner Mongolia (109.6\%), the Loess Plateau (88.6\%), and Xinjiang (81\%). Changes in solar radiation and air temperature had relatively less effect on the grasslands dynamics in each subregions.

\section{c. Contributions of climatic factors to NDVI variability in different grassland types}

For temperate grasslands, precipitation and relative humidity played absolutely dominant roles, as either the determinant factor or their average explanatory power in a percentage or significant proportion of the area (Figs. 4 and 5). Of the temperate meadow, temperate steppe, and temperate desert steppe, the precipitation dominated $36.3 \%, 44.3 \%$, and $43.4 \%$ of the areas, while relative humidity accounted for $43.5 \%, 31.2 \%$, and $25.5 \%$, respectively (Fig. 4a). The same pattern was

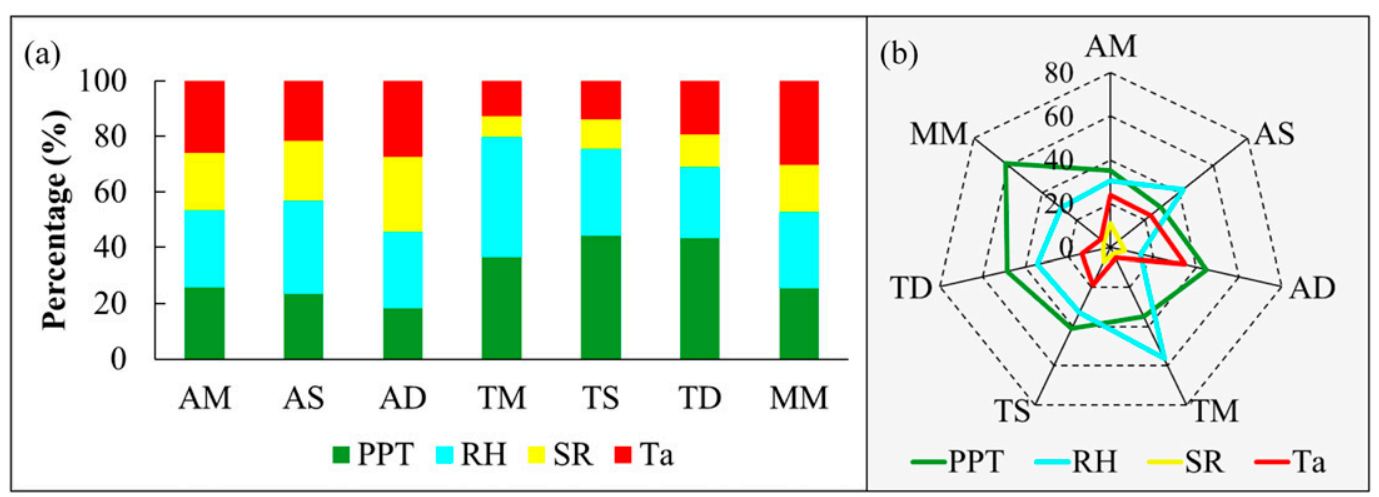

FIG. 4. (a) Area percentage of each determinant climatic factor of the whole study region and (b) the significant $(p<0.05)$ proportion area of all grids with significant effects on grassland dynamics for different grassland types (AM: alpine meadow; AS: alpine steppe; AD: alpine desert steppe; TM: temperate meadow steppe; TS: temperate typical steppe; TD: temperate desert steppe; MM: mountainous meadow). Abbreviations are defined in Fig. 1. 


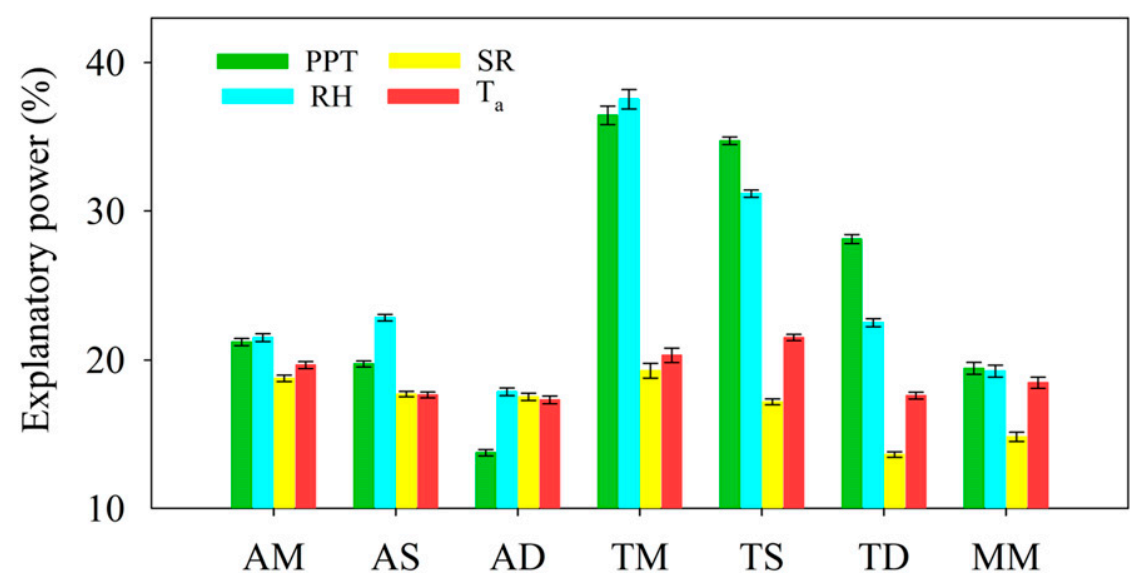

FIG. 5. Average explanatory powers of climatic factors (PPT, RH, SR, $T_{a}$ ) for grassland dynamics for each grassland type (AM, AS, AD, TM, TS, TD, MM). Bars indicate standard error. Abbreviations are defined in Figs. 1 and 4.

observed for the proportion of grids experiencing significant effect (Fig. 4b). The average explanatory powers of precipitation and relative humidity were $36.4 \%$ and $37.5 \%$ for temperate meadow, $34.7 \%$ and $31.2 \%$ for temperate typical steppe, and $28.1 \%$ and $22.5 \%$ for temperate desert steppe, respectively, showing a decrease with reduced water availability. Solar radiation and air temperature had relatively weak effects on the IAV of NDVI in temperate grasslands, with explanatory powers ranges of $19.3 \%-13.6 \%$ and $21.5 \%-17.6 \%$, respectively (Fig. 5).

As the determinant factors, precipitation and relative humidity accounted for larger percentages of areas at $25.7 \%$ and $27.7 \%$ of alpine meadows, $23.4 \%$ and $33.3 \%$ of alpine steppes, and $18.2 \%$ and $27.4 \%$ of alpine desert steppes, respectively (Fig. 4a).The average explanatory powers of climatic variables for alpine grassland showed ranges of $13.7 \%-21.2 \%$ (precipitation), $17.8 \%-22.9 \%$ (relative humidity), $17.5 \%-18.8 \%$ (solar radiation), and $17.3 \%-19.7 \%$ (air temperature), which were much less than those for temperate grasslands (Fig. 5). Climate variability explained the IAV of NDVI more in temperate grasslands than in alpine grasslands. The aggregated explanatory power of four climatic factors on the IAV of NDVI were $113.6 \%$ (temperate meadow), $104.6 \%$ (temperate steppe), 81.8\% (temperate desert steppe), $81.1 \%$ (alpine meadow), $78.0 \%$ (alpine steppe), and $66.4 \%$ (alpine desert steppe). Air temperature played a more important role in alpine grassland than in temperate grassland, with significant area proportions of more than $20 \%$ in alpine grasslands (Fig. 4b). In mountain meadows as a nonzonal vegetation type, the four climatic variables had roughly equivalent influences on the IAV of NDVI, and the proportion and average explanatory power pattern was similar to that of alpine grasslands.

\section{Discussion}

\section{a. Relative importance of climatic factors on the IAV} of NDVI

Relative humidity and precipitation played leading roles in annual grassland activity, in terms of both the explanatory ability and area percentage in the study region. These results confirmed that precipitation has a critical effect on vegetation productivity in Inner Mongolia and the Loess Plateau during the growing season (Chuai et al. 2013; Bao et al. 2014; Xie et al. 2016). Our results are consistent with previous studies finding water availability dominated vegetation activities, and vegetation activity was sensitive to water availability in water-limited ecosystems ( $\mathrm{Li}$ et al. 2015b; Y. Yao et al. 2018). Our results also indicated that relative humidity has made an equal and even larger contribution to the IAV of NDVI especially on the Tibetan Plateau. The reason is that relative humidity is a key index of atmospheric aridity (Méndez-Barroso et al. 2009; Novick et al. 2016; Sulman et al. 2016; Wang et al. 2017), which constrains plant growth and ecosystem carbon fluxes (Wu et al. 2011) by governing stomatal closure and subsequent plant carbon uptake (Novick et al. 2016; Sulman et al. 2016; Konings et al. 2017). Therefore, relative humidity plays a crucial role in affecting the interannual variations in vegetation productivity in grasslands, which should be paid much more attention in future studies.

In our study, we used the average or sum of the climatic variables in the growing season as the values to investigate the climate-NDVI relation at an annual scale. It has been suggested that some other factors at finer scales, such as precipitation seasonality and precipitation in previous year (i.e., the lag effect), may also 
impact vegetation productivity at an annual scale (Guo et al. 2015). In our study region, it has been found that the total amount of precipitation in the growing season, rather than other rainfall characteristics, is the dominant index depicting the IAV of annual primary productivity in the grassland ecosystems (Hu et al. 2018). In addition, no lag effect of precipitation on aboveground net primary productivity has been found in the study region (Guo et al. 2013). For the other climatic factors (e.g., relative humidity, solar radiation, and air temperature), their seasonal patterns are regular among years. Therefore, using growing season mean or sum for these variables is effective in detecting their relative importance to NDVI variability.

\section{b. Divergent contribution of climatic factors to NDVI variability among grasslands types and subregions}

Climate variability exerted less influence on the IAV of NDVI in alpine grasslands than that in temperate grasslands, owing to large differences between the two vegetation types in the contribution of precipitation and relative humidity. Two reasons may cause the difference between the two distinct grassland types. First, the importance of aridity on plant growth is different between the two grassland types. In the temperate grasslands, low annual precipitation in combination with relatively high air temperature make plant growth mostly constrained by water availability (Cong et al. 2017). Thus, precipitation and relative humidity, indicators of aridity, demonstrate high explanatory ability for IAV of NDVI. In comparison, the air temperature in alpine grasslands is relatively low owing to the high elevation, which largely alleviates the constraint of water availability due to low evapotranspiration under this condition. Therefore, the contributions of precipitation and relative humidity on IAV of NDVI are lower in alpine grasslands. Second, the topology in alpine grasslands, which are mostly located on the Tibetan Plateau, is more complex than that in temperate grasslands, making the spatial pattern of environmental conditions much more heterogeneous in alpine grasslands. In other words, the interactions among the environmental factors in alpine grasslands are more complex and their impacts on the IAV of NDVI are difficult to quantify. The different combinations of all vegetation types produce the divergence of the area proportion (determinant climatic factors) and explanatory ability (each climatic factor) among subregions.

\section{c. Merits and uncertainty of GDM}

GDM can detect spatial stratified heterogeneity, which mainly reflects the two-dimensional relationship between the variables. This method used in this study was based on the assumption that the IAV of vegetation activity is determined by the climatic variables (de Jong et al. 2011). GDM is found to have better performance for quantifying the contributions of independent variables to a dependent variable, owing to its independence from the linear assumption (Wang et al. 2010). Therefore, GDM is more beneficial for revealing a causal law than traditional methods. To the best of our knowledge, this study is the first attempt of using GDM to quantify the contributions of climatic factors to vegetation activities. Note that there are still some limitations of using GDM to quantify the contribution of climatic factors to the IAV of NDVI. First, GDM is a statistical model in essence and cannot fully clarify the mechanisms of the relationship of vegetation productivity and climatic variability. Further analysis and cross-validation of the results are required in conjunction with process models. Second, the total contribution of four climatic factors was less or more than $100 \%$, implying that interactions exist between different factors, which warrant further study.

\section{Conclusions}

Using the geographical detector method, we quantified the contributions of four climatic factors (precipitation, relative humidity, air temperature, solar radiation) on interannual variations in NDVI in the grasslands of northern China. We found that precipitation and relative humidity were the dominant factors controlling the NDVI variability. Importantly, in terms of both the area fraction and the relative contribution, relative humidity plays a considerable or even more important role in affecting NDVI variability than precipitation. Thus, our findings highlight the importance of atmospheric aridity to the interannual variability of vegetation productivity in grasslands of northern China, or other arid regions in the world. In addition, the accumulative explanatory power of climatic factors for NDVI variability is weaker in alpine grasslands than in the temperate grasslands. This implies that the mechanism controlling the NDVI variability is more complex in the alpine grasslands, and predicting the response of vegetation to climate change in this region would be more challenging.

Acknowledgments. This study was supported by National Key R\&D Program of China (2016YFC0501603), the National Postdoctoral Fund (2019M652935), the National Natural Science Foundation of China (Grant 31570437), and the Startup Foundation for Talented Scholars in South China Normal University. 


\section{REFERENCES}

Ahlström, A., and Coauthors, 2015: The dominant role of semi-arid ecosystems in the trend and variability of the land $\mathrm{CO}_{2}$ sink. Science, 348, 895-899, https://doi.org/10.1126/science.aaa1668.

Bai, Y., X. Han, J. Wu, Z. Chen, and L. Li, 2004: Ecosystem stability and compensatory effects in the Inner Mongolia grassland. Nature, 431, 181-184, https://doi.org/10.1038/nature02850.

Bao, G., Z. Qin, Y. Bao, Y. Zhou, W. Li, and A. Sanjjav, 2014: NDVI-based long-term vegetation dynamics and its response to climatic change in the Mongolian Plateau. Remote Sens., 6, 8337-8358, https://doi.org/10.3390/rs6098337.

Chuai, X. W., X. J. Huang, W. J. Wang, and G. Bao, 2013: NDVI, temperature and precipitation changes and their relationships with different vegetation types during 1998-2007 in Inner Mongolia, China. Int. J. Climatol., 33, 1696-1706, https:// doi.org/10.1002/joc.3543.

Cong, N., M. Shen, W. Yang, Z. Yang, G. Zhang, and S. Piao, 2017: Varying responses of vegetation activity to climate changes on the Tibetan Plateau grassland. Int. J. Biometeor., 61, 14331444, https://doi.org/10.1007/s00484-017-1321-5.

de Jong, R., S. de Bruin, A. de Wit, M. E. Schaepman, and D. L. Dent, 2011: Analysis of monotonic greening and browning trends from global NDVI time-series. Remote Sens. Environ., 115, 692-702, https://doi.org/10.1016/j.rse.2010.10.011.

Ding, J., and Coauthors, 2018: Increasingly important role of atmospheric aridity on Tibetan Alpine grasslands. Geophys. Res. Lett., 45, 2852-2859, https://doi.org/10.1002/2017GL076803.

Fan, J., H. Zhong, W. Harris, G. Yu, S. Wang, Z. Hu, and Y. Yue, 2008: Carbon storage in the grasslands of China based on field measurements of above- and below-ground biomass. Climatic Change, 86, 375-396, https://doi.org/10.1007/s10584-007-9316-6.

Friedlingstein, P., and Coauthors, 2006: Climate-carbon cycle feedback analysis: Results from the $\mathrm{C}^{4} \mathrm{MIP}$ Model Intercomparison. J. Climate, 19, 3337-3353, https://doi.org/ 10.1175/JCLI3800.1.

Guo, Q., Z. Hu, S. Li, X. Li, X. Sun, and G. Yu, 2012: Spatial variations in aboveground net primary productivity along a climate gradient in Eurasian temperate grassland: Effects of mean annual precipitation and its seasonal distribution. Global Change Biol., 18, 3624-3631, https://doi.org/10.1111/ gcb.12010.

, — - X. Li, and S. Li, 2013: Effects of precipitation timing on aboveground net primary productivity in Inner Mongolia temperate steppe (in Chinese). Acta Ecol. Sin., 33, 4808-4817, https://doi.org/10.5846/stxb201205030636.

- and Coauthors, 2015: Contrasting responses of gross primary productivity to precipitation events in a water-limited and a temperature-limited grassland ecosystem. Agric. For. Meteor., 214-215, 169-177, https://doi.org/10.1016/j.agrformet.2015.08.251.

$\mathrm{Hu}, \mathrm{Z}$., and Coauthors, 2017: Modeling and partitioning of regional evapotranspiration using a satellite-driven water-carbon coupling model. Remote Sens., 9, 54, https://doi.org/10.3390/ rs9010054.

— Q. Guo, S. Li, S. Piao, A. K. Knapp, P. Ciais, X. Li, and G. Yu, 2018: Shifts in the dynamics of productivity signal ecosystem state transitions at the biome-scale. Ecol. Lett., 21, 1457-1466, https://doi.org/10.1111/ele.13126.

Hutchinson, M. F., and T. B. Xu, 2013: ANUSPLIN Version 4.4 User Guide. Australian National University, 52 pp., http:// refhub.elsevier.com/S0048-9697(17)31044-6/rf0110.

Keenan, T. F., D. Y. Hollinger, G. Bohrer, D. Dragoni, J. W. Munger, H. P. Schmid, and A. D. Richardson, 2013: Increase in forest water-use efficiency as atmospheric carbon dioxide concentrations rise. Nature, 499, 324-327, https://doi.org/ 10.1038/nature12291.

Konings, A. G., A. P. Williams, and P. Gentine, 2017: Sensitivity of grassland productivity to aridity controlled by stomatal and xylem regulation. Nat. Geosci., 10, 284-288, https://doi.org/ 10.1038/ngeo2903.

Lee, X., and Coauthors, 2011: Observed increase in local cooling effect of deforestation at higher latitudes. Nature, 479, 384387, https://doi.org/10.1038/nature10588.

Li, S., S. Yang, X. Liu, Y. Liu, and M. Shi, 2015a: NDVI-based analysis on the influence of climate change and human activities on vegetation restoration in the Shaanxi-Gansu-Ningxia region, central China. Remote Sens., 7, 11163-11182, https:// doi.org/10.3390/rs70911163.

Li, Z., Y. Chen, W. Li, H. Deng, and G. Fang, 2015b: Potential impacts of climate change on vegetation dynamics in Central Asia. J. Geophys. Res., 120, 12345-12356, https://doi.org/ 10.1002/2015JD023618.

Liu, R., R. Shang, Y. Liu, and X. Lu, 2017: Global evaluation of gap-filling approaches for seasonal NDVI with considering vegetation growth trajectory, protection of key point, noise resistance and curve stability. Remote Sens. Environ., 189, 164-179, https://doi.org/10.1016/j.rse.2016.11.023.

Luo, W., J. Jasiewicz, T. Stepinski, J. Wang, C. Xu, and X. Cang, 2016: Spatial association between dissection density and environmental factors over the entire conterminous United States. Geophys. Res. Lett., 43, 692-700, https://doi.org/ 10.1002/2015GL066941.

Mao, J., X. Shi, P. E. Thornton, S. Piao, and X. Wang, 2012: Causes of spring vegetation growth trends in the northern mid-high latitudes from 1982 to 2004. Environ. Res. Lett., 7, 014010, https://doi.org/10.1088/1748-9326/7/1/014010.

Méndez-Barroso, L. A., E. R. Vivoni, C. J. Watts, and J. C. Rodríguez, 2009: Seasonal and interannual relations between precipitation, surface soil moisture and vegetation dynamics in the North American monsoon region. J. Hydrol., 377, 59-70, https://doi.org/10.1016/j.jhydrol.2009.08.009.

Nemani, R. R., C. D. Keeling, H. Hashimoto, W. M. Jolly, S. C. Piper, C. J. Tucker, R. B. Myneni, and S. W. Running, 2003: Climate-driven increases in global terrestrial net primary production from 1982 to 1999 . Science, 300, 1560-1563, https:// doi.org/10.1126/science.1082750.

Novick, K. A., and Coauthors, 2016: The increasing importance of atmospheric demand for ecosystem water and carbon fluxes. Nat. Climate Change, 6, 1023-1027, https://doi.org/10.1038/ nclimate 3114.

Peng, S., and Coauthors, 2013: Precipitation amount, seasonality and frequency regulate carbon cycling of a semi-arid grassland ecosystem in Inner Mongolia, China: A modeling analysis. Agric. For. Meteor., 178-179, 46-55, https://doi.org/10.1016/ j.agrformet.2013.02.002.

Piao, S., and Coauthors, 2014: Evidence for a weakening relationship between interannual temperature variability and northern vegetation activity. Nat. Commun., 5, 5018, https:// doi.org/10.1038/ncomms6018.

_ and Coauthors, 2015: Detection and attribution of vegetation greening trend in China over the last 30 years. Global Change Biol., 21, 1601-1609, https://doi.org/10.1111/gcb.12795.

Seddon, A. W., M. Macias-Fauria, P. R. Long, D. Benz, and K. J. Willis, 2016: Sensitivity of global terrestrial ecosystems to climate variability. Nature, 531, 229-232, https://doi.org/10.1038/ nature16986. 
Sulman, B. N., D. T. Roman, K. Yi, L. Wang, R. P. Phillips, and K. A. Novick, 2016: High atmospheric demand for water can limit forest carbon uptake and transpiration as severely as dry soil. Geophys. Res. Lett., 43, 9686-9695, https://doi.org/ 10.1002/2016GL069416.

Sun, J., and X. Qin, 2016: Precipitation and temperature regulate the seasonal changes of NDVI across the Tibetan Plateau. Environ. Earth Sci., 75, 291, https://doi.org/10.1007/s12665015-5177-x.

Ukkola, A. M., I. C. Prentice, T. F. Keenan, A. I. J. M. van Dijk, N. R. Viney, R. B. Myneni, and J. Bi, 2016: Reduced streamflow in water-stressed climates consistent with $\mathrm{CO}_{2}$ effects on vegetation. Nat. Climate Change, 6, 75-78, https://doi.org/ 10.1038/nclimate2831.

Wang, J.-F., X.-H. Li, G. Christakos, Y.-L. Liao, T. Zhang, X. Gu, and X.-Y. Zheng, 2010: Geographical detectors-based health risk assessment and its application in the neural tube defects study of the Heshun Region, China. Int. J. Geogr. Inf. Sci., 24, 107-127, https://doi.org/10.1080/13658810802443457.

_ , T.-L. Zhang, and B.-J. Fu, 2016: A measure of spatial stratified heterogeneity. Ecol. Indic., 67, 250-256, https://doi.org/ 10.1016/j.ecolind.2016.02.052.

Wang, W., and J. Fang, 2009: Soil respiration and human effects on global grasslands. Global Planet. Change, 67, 20-28, https:// doi.org/10.1016/j.gloplacha.2008.12.011.

Wang, X., T. Wang, D. Liu, H. Guo, H. Huang, and Y. Zhao, 2017: Moisture-induced greening of the South Asia over the past three decades. Global Change Biol., 23, 4995-5005, https:// doi.org/10.1111/gcb.13762.

Wu, Z., P. Dijkstra, G. W. Koch, J. Peñuelas, and B. A. Hungate, 2011: Responses of terrestrial ecosystems to temperature and precipitation change: A meta-analysis of experimental manipulation. Global Change Biol., 17, 927-942, https://doi.org/ 10.1111/j.1365-2486.2010.02302.x.

Xie, B., X. Jia, Z. Qin, J. Shen, and Q. Chang, 2016: Vegetation dynamics and climate change on the Loess Plateau, China:
1982-2011. Reg. Environ. Change, 16, 1583-1594, https:// doi.org/10.1007/s10113-015-0881-3.

$\mathrm{Xu}, \mathrm{L}$., and Coauthors, 2013: Temperature and vegetation seasonality diminishment over northern lands. Nat. Climate Change, 3, 581-586, https://doi.org/10.1038/nclimate1836.

Yamori, W., K. Hikosaka, and D. A. Way, 2014: Temperature response of photosynthesis in $\mathrm{C} 3, \mathrm{C} 4$, and CAM plants: Temperature acclimation and temperature adaptation. Photosynth. Res., 119, 101-117, https://doi.org/10.1007/s11120-013-9874-6.

Yao, J., Y. Chen, Y. Zhao, W. Mao, X. Xu, Y. Liu, and Q. Yang, 2018: Response of vegetation NDVI to climatic extremes in the arid region of Central Asia: A case study in Xinjiang, China. Theor. Appl. Climatol., 131, 1503-1515, https://doi.org/ 10.1007/s00704-017-2058-0.

Yao, Y., and Coauthors, 2018: Spatiotemporal pattern of gross primary productivity and its covariation with climate in China over the last thirty years. Global Change Biol., 24, 184-196, https://doi.org/10.1111/gcb.13830.

Yu, G. R., H. L. He, and X. A. Liu, 2004: Atlas of Spatial Information in Chinese Terrestrial Ecosystems: Climate Volume (in Chinese). Meteorology Press, 91-286.

Zhao, W., Z. Hu, S. Li, Q. Guo, Z. Liu, and L. Zhang, 2017: Comparison of surface energy budgets and feedbacks to microclimate among different land use types in an agro-pastoral ecotone of northern China. Sci. Total Environ., 599-600, 891898, https://doi.org/10.1016/j.scitotenv.2017.04.200.

Zhou, C., J. Chen, and S. Wang, 2018: Examining the effects of socioeconomic development on fine particulate matter $\left(\mathrm{PM}_{2.5}\right)$ in China's cities using spatial regression and the geographical detector technique. Sci. Total Environ., 619-620, 436-445, https://doi.org/10.1016/j.scitotenv.2017.11.124.

Zhu, P., Q. Zhuang, P. Ciais, L. Welp, W. Li, and Q. Xin, 2017: Elevated atmospheric $\mathrm{CO}_{2}$ negatively impacts photosynthesis through radiative forcing and physiology-mediated climate feedbacks. Geophys. Res. Lett., 44, 1956-1963, https://doi.org/ 10.1002/2016GL071733. 